\title{
Deux disques de musique de luths d'Afghanistan
}

\section{Pribislav Pitoëff}

\section{OpenEdition}

\section{Journals}

Édition électronique

URL : http://journals.openedition.org/ethnomusicologie/1334

ISSN : 2235-7688

Éditeur

ADEM - Ateliers d'ethnomusicologie

Édition imprimée

Date de publication : 1 décembre 1996

Pagination : 374-376

ISBN : 978-2-8257-0559-9

ISSN : $1662-372 \mathrm{X}$

Référence électronique

Pribislav Pitoëff, «Deux disques de musique de luths d'Afghanistan », Cahiers d'ethnomusicologie [En ligne], 9 | 1996, mis en ligne le 05 janvier 2012, consulté le 22 avril 2019. URL : http:// journals.openedition.org/ethnomusicologie/1334

Ce document a été généré automatiquement le 22 avril 2019.

Tous droits réservés 


\title{
Deux disques de musique de luths d'Afghanistan
}

\author{
Pribislav Pitoëff
}

\section{RÉFÉRENCE}

Afghanistan. Le rubâb de Hérat. Mohammad Rahim Khushnawaz. Enregistrements (1974) et notice de John Baily. 1 CD AIMP XXV (70'17), VDE 699, 1993.

Afghanistan. Rubâb et Dutâr.Enregistrements: Radio France (1995); notice de John Baily. 1 CD OCORA C560080 (77'55), 1995.

1 La parution rapprochée de ces deux disques, à moins de deux ans d'intervalle, est à remarquer pour trois raisons. Tout d'abord, ils présentent des aspects de la musique de Hérat, important et ancien centre culturel du Khorassan afghan, situé non loin de la frontière persane. D'autre part, le même musicien, Mohammad Rahim Khushnawaz, figure dans les deux publications. Enfin, celles-ci ont été réalisées toutes deux sous la responsabilité scientifique de John Baily. Ce dernier est un spécialiste de la musique de Hérat où, depuis 1973, il a fait de fréquents et parfois longs terrains. Après deux articles, il a publié un ouvrage important sur cette musique (Music of Afghanistan: Professional Musicians in the City of Herat [avec deux cassettes audio]. Cambridge: Cambridge University Press, 1988); de plus, il est lui-même un praticien talentueux de ce répertoire.

2 Le premier disque, Afghanistan. Le rubâb de Hérat, est intégralement consacré à Ustad («maître») Mohammad Rahim Khushnawaz, héritier d'une famille de musiciens professionnels depuis plusieurs générations et lui-même artiste de premier plan. Le rubâb , considéré par les Afghans comme leur instrument emblématique, est un luth échancré, monté avec trois cordes mélodiques en boyau ou en nylon, deux cordes bourdons, et une quinzaine de cordes sympathiques. La notice apporte des précisions sur la spécificité du rubâb de Hérat.

3 Mohammad Rahim Khushnawaz présente ici deux facettes de son répertoire: la musique traditionnelle de Hérat (qui, tout en puisant aux sources de la musique populaire de la 
région, se rapproche de la musique d'art persane ) et la musique instrumentale classique de Kaboul (assez fortement influencée par la musique savante hindoustanie) .

4 Les onze premières pièces du disque appartiennent au premier style qui, à l'origine, était pratiqué sur le dutâr hérati, un luth à long manche et à deux cordes. Les huit premières d'entre elles sont jouées en solo, les trois suivantes sont accompagnées aux tabla (le couple de tambours indien). Une seule pièce appartient à un répertoire spécifiquement instrumental, les autres sont des mélodies de chansons de diverses natures (chant soufi, chants de mariage, épopée populaire...). La pièce 9, qui dure plus de treize minutes, est un excellent «pot-pourri» composé par Mohammad Rahim. Les deux dernières pièces, d'une durée de dix minutes chacune, représentent le style dit «klâsik», venu de Kaboul - et, au delà, de l'Inde du Nord.

5 Par rapport à la musique des professionnels que l'on peut (ou du moins que l'on pouvait) entendre in situ (dans les maisons de thé et les mariages, ou même dans les salles de concert), on peut regretter l'absence de l'armunia (petit harmonium indien portatif à soufflerie manuelle), et, bien entendu, celle du chant, tous deux éléments omniprésents dans la pratique usuelle de cette musique. En effet, les enregistrements ont été faits à Hérat, certes, mais hors situation, dans une chambre d'hôtel. Précisons toutefois que les pièces instrumentales seules, notamment les morceaux dénommés naghme-ye kashâl et les sections instrumentales, plus ou moins longuement développées entre les parties chantées, figurent dans les situations de jeu normales.

6 Cette légère réserve mise à part, Mohammad Rahim est sans conteste un très grand musicien, et tout amateur de bonne musique trouvera amplement son bonheur à l'audition de ce disque. Ajoutons que la notice, excellente, nous renseignant sur la ville et les gens de Hérat, les différents répertoires, le rubâb, le musicien, et donnant une analyse parfois détaillée de chaque pièce, enrichit encore cette publication.

7 Les deux musiciens, tous deux professionnels - bien que Mohammad Rahim, plus érudit, le soit de tradition familiale alors que Gada Mohammad vient du monde des amateurs jouent ensemble depuis de nombreuses années. Instrumentistes et instruments se complètent très heureusement, le timbre métallique du dutâr, accordé une octave plus haut, contrastant avec celui, plus rond, du rubâb.

8 Les pièces jouées ici appartiennent aux deux répertoires, dénommés ici musique locale de Hérat et musique savante de Kaboul, présentés sur l'autre disque. Elles sont toutes accompagnées par les tabla. Les quatre premières sont consacrées au style de Hérat, deux pour les deux luths, les deux autres pour chacun de ces instruments. Les cinq suivantes sont du style «klâsik» de Kaboul, deux par le rubâb seul, une par le dutâr seul, encadrées par deux morceaux dans lesquels figurent les deux instruments.

9 Les enregistrements ont été faits dans un studio de Radio France au lendemain d'un très beau concert que les amateurs attendaient depuis des années, donné au Théâtre de la Ville à Paris en février 1995. Les quelques invités venus assister à la séance pour encourager les artistes, n'apportent toutefois pas à l'enregistrement le même charme que les interventions des deux canaris soutenant celle de l'autre disque (plages 9 à 12). La notice, bien que moins complète que celle du premier disque (8 pages contre 14 de texte en français), est solide. Ce disque, qui offre évidemment une plus grande variété de timbres que l'autre, enrichit grandement notre appréhension de la musique de Hérat.

Signalons que ces deux publications appliquent fort bien l'une des recommandations formulées ici même par Jean During concernant la publication de musiques 
traditionnelles: le réalisateur du disque doit avoir «outre une oreille d'artiste, une profonde connaissance du répertoire et surtout une longue fréquentation des musiciens, afin de choisir les meilleurs...» (Cahiers de musiques traditionnelles 5, 1992: 313).

11 Il nous reste à exprimer le souhait que John Baily trouvera dans ses archives matière à faire un autre disque avec ces deux artistes, accompagnés cette fois du groupe complet (chanteur, armunia, voire d'autre(s) luths) et jouant cette musique, live, dans un mariage hérati. 